\title{
Medicinal systems of complementary and alternative medicine: a cross-sectional survey at a pediatric emergency department
}

\author{
Zuzak, T J ; Zuzak-Siegrist, I ; Rist, L ; Staubli, G ; Simões-Wüst, Ana Paula
}

\begin{abstract}
OBJECTIVE: The purpose of this study was to find out which experiences adults are making while treating children with complementary and alternative medicine (CAM) therapies in Germanspeaking Switzerland. DESIGN AND SUBJECTS: A cross-sectional survey was performed on adults accompanying the children presenting to an urban, tertiary pediatric emergency department in Zurich; $71 \%$ of the distributed questionnaires (1143 of 1600) could be used for data analysis. The respondents were asked about their experiences while treating the child with CAM and-for comparison reasons-with conventional medicine (CM). RESULTS: The respondents perceived the effectiveness of CAM therapies in general to be inferior to that of CM, although $49 \%$ of all respondents stated that CAM therapies were more effective than CM in certain cases/against certain diseases and $13 \%$ that CAM therapies were as effective as CM. Higher frequency of use and lower compliance were observed in the case of CAM, relatively to CM. Respondents described the direct costs for the patient of both types of medicine to be comparable. Ninety-three percent (93\%) of the respondents experienced no side-effects with CAM therapies, whereas only $52 \%$ of the respondents stated the same about CM therapies; the observed side-effects of CAM were weaker than those of CM. Homeopathy was the most frequently used form of CAM (77\% of all CAM users), followed by herbal medicine (64\%), anthroposophic medicine (24\%), Traditional Chinese Medicine (13\%), Ayurveda (5\%), and others (34\%). CONCLUSIONS: From the respondents' point of view, the most marked difference between CAM- and CM therapies concerns the frequency and intensity of side-effects, which were markedly higher in the latter case. The respondents made use of a wide variety of CAM therapies.
\end{abstract}

DOI: https://doi.org/10.1089/acm.2009.0601

Posted at the Zurich Open Repository and Archive, University of Zurich ZORA URL: https://doi.org/10.5167/uzh-45528

Journal Article

Originally published at:

Zuzak, T J; Zuzak-Siegrist, I; Rist, L; Staubli, G; Simões-Wüst, Ana Paula (2010). Medicinal systems of complementary and alternative medicine: a cross-sectional survey at a pediatric emergency department. Journal of Alternative and Complementary Medicine, 16(4):473-479.

DOI: https://doi.org/10.1089/acm.2009.0601 


\title{
Medicinal Systems of Complementary and Alternative Medicine: A Cross-Sectional Survey at a Pediatric Emergency Department
}

\author{
Tycho Jan Zuzak, M.D., ${ }^{1,2}$ Isabelle Zuzak-Siegrist, M.D., ${ }^{2}$ Lukas Rist, Ph.D., ${ }^{3}$ \\ Georg Staubli, M.D., ${ }^{2}$ and Ana Paula Simões-Wüst, Ph.D. ${ }^{3}$
}

\begin{abstract}
Objective: The purpose of this study was to find out which experiences adults are making while treating children with complementary and alternative medicine (CAM) therapies in German-speaking Switzerland.

Design and subjects: A cross-sectional survey was performed on adults accompanying the children presenting to an urban, tertiary pediatric emergency department in Zurich; 71\% of the distributed questionnaires (1143 of 1600) could be used for data analysis. The respondents were asked about their experiences while treating the child with CAM and-for comparison reasons-with conventional medicine (CM).

Results: The respondents perceived the effectiveness of CAM therapies in general to be inferior to that of $\mathrm{CM}$, although $49 \%$ of all respondents stated that CAM therapies were more effective than CM in certain cases/against certain diseases and 13\% that CAM therapies were as effective as CM. Higher frequency of use and lower compliance were observed in the case of CAM, relatively to CM. Respondents described the direct costs for the patient of both types of medicine to be comparable. Ninety-three percent $(93 \%)$ of the respondents experienced no side-effects with CAM therapies, whereas only $52 \%$ of the respondents stated the same about CM therapies; the observed side-effects of CAM were weaker than those of CM. Homeopathy was the most frequently used form of CAM (77\% of all CAM users), followed by herbal medicine $(64 \%)$, anthroposophic medicine $(24 \%)$, Traditional Chinese Medicine (13\%), Ayurveda (5\%), and others (34\%).

Conclusions: From the respondents' point of view, the most marked difference between CAM- and CM therapies concerns the frequency and intensity of side-effects, which were markedly higher in the latter case. The respondents made use of a wide variety of CAM therapies.
\end{abstract}

\section{Introduction}

$\mathbf{T}$ HE USE OF COMPLEMENTARY and alternative medicine (CAM) - a group of medical methods, practices, and products not considered to be part of conventional medicinehas become popular during the last few decades. ${ }^{1-3}$ Previous surveys on the frequency of CAM use by children suffering from chronic illnesses have revealed values between $46 \%$ and $70 \%{ }^{4-7}$ Surveys on pediatric emergency departments in the United States and Canada showed that $12 \%-15 \%$ of the parents were treating their child with CAM. ${ }^{8-10}$ A recent survey performed in Germany with parents of pediatric oncology patients revealed that approximately $35 \%$ of these were using CAM. ${ }^{11}$

CAM is often used in Switzerland. ${ }^{12-15}$ A survey published in 2002 described that $30 \%$ of the Swiss people did use some form of CAM: $12 \%$ had used homeopathy, $11 \%$ had used Traditional Chinese Medicine (TCM) or acupuncture, 5\% herbal medicine (phytotherapy), 2\% anthroposophic medicine, and $1 \%$ neuraltherapy. ${ }^{16}$ The use of CAM in Switzerland, its efficacy, appropriateness, and cost-effectiveness have been evaluated within the frames of a federal program (Complementary Medicine Evaluation Program, PEK), which revealed that CAM was associated with a higher patient

\footnotetext{
${ }^{1}$ Department of Pediatric Oncology and Haematology, University Children's Hospital Essen, Essen, Germany.

${ }^{2}$ University Children's Hospital of Zurich, Zurich, Switzerland.

${ }^{3}$ Research Department, Paracelsus Hospital Richterswil, Richterswil, Switzerland.

This is a full-text article of an abstract accepted for presentation at ICCMR 2010 in Tromsø, Norway.
} 
satisfaction, weaker/less frequent side-effects, and lower costs than conventional medicine (CM) ${ }^{15,17-20}$ The use of CAM by children in Switzerland has just started to be unveiled. A previous study performed at the intensive care unit of the Children's Hospital of Zurich revealed that $18 \%$ of the parents of critically ill pediatric patients applied some form of CAM. ${ }^{21}$ In a previous report about the present survey, which was performed at the emergency department of the same hospital, $58 \%$ of all respondents (665 of 1143 ) stated that their child was using/had used some form of CAM therapies. ${ }^{22}$

The aim of the present work was to reveal the experiences that adults-mainly parents-accompanying pediatric patients presenting to a pediatric, urban, tertiary emergency department were/are having while treating their child with CAM. The questionnaires used included items on (1) perceived effectiveness, (2) side-effects, (3) patients' compliance, (4) frequency of use, (5) costs, (6) reimbursement by health insurance, and (7) description of the CAM therapies used. Although the survey mainly addresses the experiences with $\mathrm{CAM}$, in some cases and for comparison reasons, the respondents were asked to describe their experiences with $\mathrm{CM}$ as well.

\section{Subjects and Methods}

The present work is an analytical cross-sectional survey of the adults-mainly parents-accompanying the children presenting to the pediatric emergency department of the University Children's Hospital of Zurich between October 2006 and March 2007. The study was approved and conducted in accordance with the ethical standards set by the Hospital Ethical Review Board. Questionnaires were offered by the ward clerk to parents (or other caretakers) while these individuals were registering the child. Caretakers were asked to fill out the questionnaire, sign the consent form, and hand it back to the ward clerk, the nurse, or the front desk before leaving the department. German, English, French, and Italian versions of the patient information sheet, consent form, and questionnaire were available. The questionnaire included 34 multiple-choice questions, addressed the situation of pediatric patients, and was completely anonymous. ${ }^{22}$ Exclusion criteria were (1) previously filled-out questionnaire; (2) inability of the respondent to read or write German, English, French, or Italian; (3) respondent was accompanying resuscitation/ emergency patients; (4) lack of respondent (i.e., pediatric patient unaccompanied by a parent or another caretaker); and (5) respondent was accompanying a patient with emotional issues such as child abuse or psychiatric problems. All other accompanying persons were eligible for the study.

A questionnaire comprising 34 multiple-choice questions was used in which homeopathy, herbal medicine, anthroposophic medicine, Traditional Chinese Medicine (including acupuncture), and Ayurveda were specified. A pilot questionnaire, distributed to 20 families, was conducted to ensure the readability and clarity of the questions. Thereafter, minor revisions of the questionnaire-mainly involving its layoutwere made. Patients' and respondents' demographic characteristics as well as behavior toward vaccination of CAM users and nonusers have been published elsewhere. ${ }^{22,23}$

Questionnaires returned with fewer than $50 \%$ of the questions answered or with no answers to the specific questions were excluded from the analysis. The remaining survey results were entered into a computerized database using Remark Office OMR 6.0.4 (Gravic Inc., Malvern PA). Data entry was performed using a Microsoft Excel database, and all data were analyzed using SPSS for Windows version 14 (SPSS Inc., Chicago IL). The data on ordinal multiple-choice answer to some questions have been converted to fit in a range from 0 to 1 and averaged, in order to obtain values representative of either CAM or CM. Pearson's $\chi^{2}$ and Mann-Whitney $U$ tests (always two-sided) were used to determine statistically significant differences between the representative values of CAM and CM, with a $p$-value of less than 0.05 considered to be statistically significant. Throughout the article, quotation marks are used to refer to the original text of the questionnaire (English version).

\section{Results}

\section{Demographic characteristics of the respondents}

Between October 2006 and March 2007, 1143 questionnaires (71\% of those distributed) were available for analysis, $95 \%$ of which were in German. Fifteen $(15 ; 0.9 \%$ of those distributed) returned questionnaires were not entered into the database as fewer than $50 \%$ of the questions were answered. Questionnaires were filled out by patients' mothers $(65 \%, n=701)$, fathers $(32 \%, n=353)$, or others $(1 \%, n=12)$. The sociodemographic characteristics of the respondentsincluding a comparison between the characteristics of CAMusers and nonusers-have been previously published in detail. $^{22}$ In brief, the children corresponding to the respondents were 5.6 years old, the mothers were 34.7 years old, and the fathers were 37.4 years old. Fifty-five percent $(55 \%)$ of the children were boys, $89 \%$ of all children lived in intact families, and 92\% were born in Switzerland. Fifty-four percent $(54 \%)$ and $45 \%$ of the respondents reported that the father and the mother, respectively, had a high school education.

\section{Effectiveness and tolerability of CAM- and CM therapies}

How often CAM therapies "did have an effect" was described as "always" by $38 \%$ of the respondents $(n=242)$, "sometimes" by 52\% $(n=331)$, "rarely" by 3\% $(n=19)$, and as "never" by $5 \%(n=33)$; in parallel, how often CM therapies "did have an effect" was answered as "always" by $62 \%$ $(n=473)$, "sometimes" by $34 \%(n=262)$, "rarely" by $1 \%$ $(n=11)$, and "never" by $2 \%(n=14)$ of the respondents. When these results were translated in a 0-to- 1 scale (range: "never" $=0$ to "always" $=1$; see Fig. 1), the mean values for CAM and CM were 0.76 and $0.85(p<0.001)$ (i.e., the respondents rated the perceived effectiveness of CAM therapies to be statistically significantly lower than that of CM therapies). When asked to judge CAM therapies in comparison with CM, approximately half of the respondents $(49 \%$, $n=370$ ) reported CAM therapies to be "more effective in certain cases/against certain disorders," $13 \%$ to have an "equivalent effect" $(n=99)$, and $23 \%(n=174)$ to be "less effective" than CM therapies; $3 \%(n=26)$ of the respondents stated that CAM therapies are "not effective."

Noticed side-effects of CAM therapies were described as "strong" by $1.4 \%(n=9)$ and "weak" by $6 \%(n=38)$, whereas $93 \%$ of the respondents $(n=580)$ indicated "no side effects." 


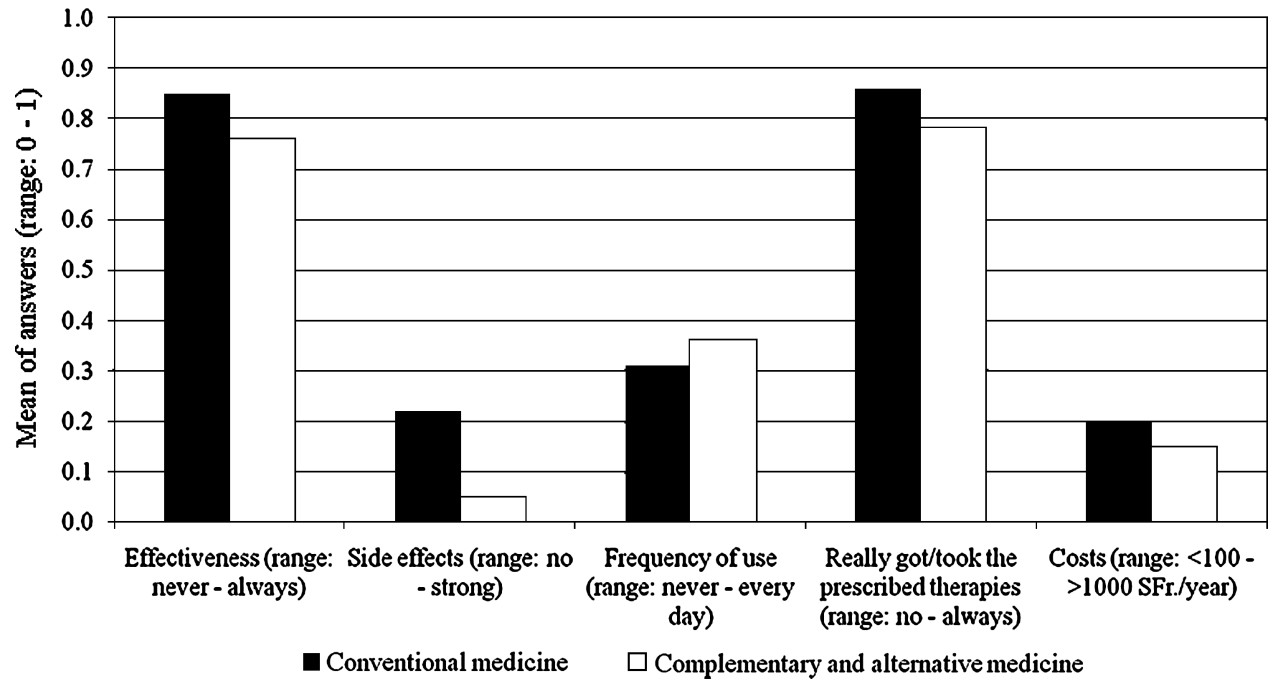

FIG. 1. Respondents' perception of complementary and alternative medicine (CAM)- and conventional medicine (CM) therapies. Respondents were asked to rate perceived effectiveness, sideeffects, frequency of use, compliance to, and direct costs of $\mathrm{CM}$ therapies (black columns) and CAM therapies (white columns). Data from ordinal multiple-choice answers have been converted to fit in a range from 0 to 1 and calculated as described under Subjects and Methods.
The side-effects of CM therapies were reported to be "strong" by $10 \%(n=73)$ and "weak" by $38 \%(n=284)$; "no sideeffects" was crossed by $52 \%(n=381)$ of the respondents. The averaged result (range: "no side-effects" $=0$ to "strong side-

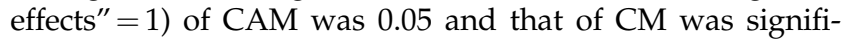
cantly and markedly higher, namely, 0.22 ( $p<0.001$, Fig. 1).

\section{Frequency of use of and compliance to CAM- and CM therapies}

Frequency of use of CAM therapies was specified as "every day" by $8 \%$ of the respondents $(n=57), " 1-4$ times a week" by $7 \%(n=45)$, " $1-3$ times a month" by 13\% $(n=89)$, "1-10 times per year" by $55 \%(n=368)$, and "never" by $17 \%(n=116)$. On the other hand, the frequency of use of CM therapies was described as "every day" by $9 \%(n=75)$, "1-4 times a week" by $2 \%(n=12)$, " $1-3$ times a month" by $6 \%(n=51)$, " $1-10$ times per year" by $71 \%(n=570)$, and "never" by $12 \%(n=93)$ of the respondents. The averaged results (range: "never" $=0$ to "every day" =1) for CAM- and CM therapies were 0.36 and $0.31(p<0.001)$, respectively, showing a significantly higher use of CAM than of CM (Fig. 1).

To compare the compliance toward CAM and CM, the questionnaires included an item on whether the child did "really get/take the prescribed therapies." Concerning CAM therapies, $8 \%$ of the respondents marked "no" $(n=53), 3 \%$ answered "rarely" $(n=19), 9 \%$ "in part" $(n=57), 25 \%$ $(n=160)$ "mostly," and 54\% $(n=342)$ "always." In the case of CM therapies, $4 \%$ of the respondents answered "no" $(n=32)$, $2 \%$ "rarely" $(n=16), 5 \%(n=36)$ "in part," 23\% $(n=178)$ "mostly," and 56\% $(n=492)$ "always." The averaged result (range: "no" $=0$ to "always" $=1$ ) of CAM was 0.78 and that of $\mathrm{CM}$ was $0.86(p<0.001)$, indicating a significantly higher compliance toward CM (Fig. 1).

\section{Costs of CAM and CM}

The respondents were asked to estimate the annual direct costs of CAM and CM concerning the respective child, "without counting the contributions paid by their health insurance and without insurance premiums." The direct costs of CAM therapies were "1-100 SFr" (Swiss Francs, SFr $=1.50$ Euros) for $55 \%$ of the respondents $(n=361)$, "100-200 SFr" for
$23 \%(n=151)$, “200-500 SFr" for 15\% $(n=101)$, “500-1000

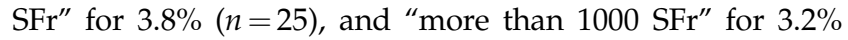
$(n=21)$. The direct costs of CM were: "1-100 SFr" for $46 \%$ ( $n=348)$ of the respondents, "100-200 SFr" for $24 \%(n=181)$, "200-500 SFr" for 21.8\% $(n=164)$, "500-1000 SFr" for $4.8 \%$ $(n=36)$, and "more than $1000 \mathrm{SFr}^{\prime}$ for $3.2 \%(n=24)$. The averaged results (range: "1-100 SFr." $=0$ to "more than 1000 $\mathrm{SFr}^{\prime \prime}=1$ ) for CAM and CM were 0.15 and 0.20 , respectively. Although the difference was not statistically significant $(p=0.289)$, there was a tendency for slightly higher costs in the case of CM- than in the case of CAM therapies (Fig. 1).

The questionnaires included an item on whether "the child's health insurance pay[s] for complementary therapies." Thirty-six percent $(36 \%, n=373)$ of all respondents believed that nearly all costs of CAM therapies would be covered by their insurance, $22 \%(n=232)$ knew that at least a part of the CAM therapies were balanced, $5.7 \%(n=59)$ described that no CAM therapies were balanced by their insurance, and $36 \%$ $(n=375)$ did not know. Sixty-five percent $(65 \%, n=412)$ of all CAM users had an additional insurance for CAM, 18\% $(n=114)$ had none, and $17 \%(n=112)$ did not know whether they had one (Fig. 2). In contrast, only 37\% $(n=154)$ of the non-CAM users had an additional insurance for CAM therapies, $25 \%(n=105)$ had none, and 38\% $(n=158)$ did not know whether they had one.

Thirty-two percent $(32 \%, n=313)$ of all respondents were convinced that all CAM therapies should be included in the basic health insurance, $29 \%(n=289)$ stated that "only the most usual complementary therapies" and 33\% $(n=324)$ that "only the ones prescribed or practiced by a doctor" should be reimbursed. However, almost all respondents (96\% of the CAM users and $89 \%$ of the nonusers) were of the opinion that some complementary therapies should be included in basic health insurance. Only $6 \%(n=64)$ of all respondents would refuse inclusion of any CAM in the basic health insurance.

\section{Different types of CAM}

Fifty-eight percent $(58 \%, 665$ of 1143) of all respondents admitted that their child had used some form of CAM. ${ }^{22}$ Seventyseven percent $(77 \%)$ of these CAM users used homeopathy, 
FIG. 2. How the respondents had organized and thought about the reimbursement of complementary and alternative medicine (CAM) therapies. Respondents were asked if the patients' insurance would reimburse CAM therapies, if patients had additional insurance for CAM, and whether they thought CAM therapies should be included in the basic health insurance. Data from conventional medicine users (black columns) and CAM users (white columns) are shown percentage of all answers. separately, in both cases as

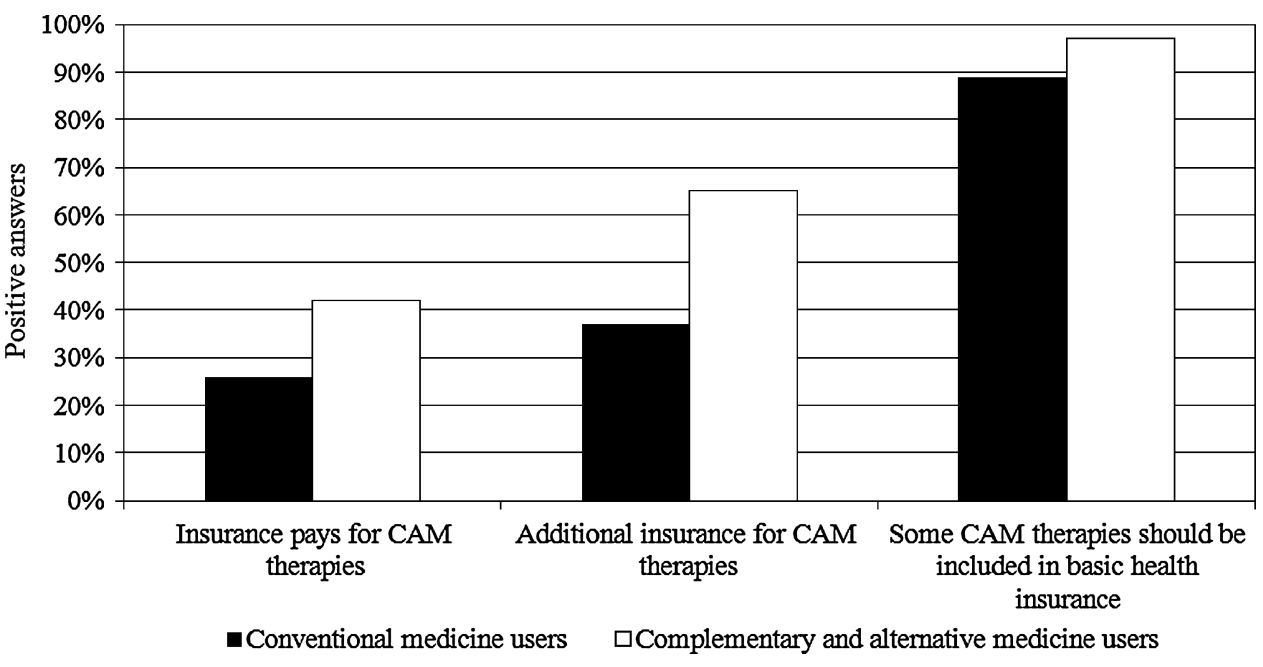

and "others" (5.3\%, $n=49)$. The answers of CAM users and nonusers were comparable (not shown).

used herbal medicine, $24 \%$ used anthroposophic medici $13 \%$ used TCM, 5\% used Ayurveda, and 34\% used other CAM therapies (various answers possible). Respondents were also asked to specify which therapies exactly-within these wide categories - the pediatric patients had received, by marking or not a long list of items (Table 1).

\section{Self-medication versus therapies prescribed by physicians}

Respondents were asked to specify who had prescribed the respective therapies, with the possibility to mark "automedication (family members, friends)." A ratio between therapies used as self-medication and therapies prescribed by "pediatricians, family doctors, therapists, children's hospital doctors, emergency doctors/emergency calls" was calculated to quantify the relative rate of self-medication (Table 1) and is referred to in the present article as "S/P-factor." High rates of self-medication (S/P-factor higher than 1.5) were found in some forms of homeopathy (mixed medicaments on sale and Bach flower remedies) and phytotherapy (only compresses), as well as in Ayurveda, whereas nearly three of four therapies were not prescribed by a medical doctor, and in several of the CAM therapies mentioned under others. CAM forms with lower rates of self-medication were phytotherapy (S/P-factor $0.8)$, classical homeopathy (1.0), anthroposophic medicine (1.3), and TCM (1.0).

\section{Parental requirements concerning CAM therapies}

The respondents were asked "which medical systems should be included in the basic health insurance" (Fig. 3), with the possibility to mark "classical medicine" (chosen by $89 \%$ of all respondents, $n=846)$, "homeopathy" (72\%, $n=687)$, "phytotherapy (herbal medicine)" (43\%,n=407), "anthroposophic medicine" $(23 \%, n=218)$, “Chinese medicine (TCM), acupuncture" $(50 \%, n=476)$, neuraltherapy $(17 \%, n=164)$, and/or "others" $(5.6 \%, n=53)$.

Some of the respondents were convinced that some CAM therapies should be taught at the universities (Fig. 3), namely "homeopathy" (71\%, $n=661)$, "phytotherapy (herbal medicine)" $(41 \%, n=382)$, "anthroposophic medicine" $(26 \%$, $n=239)$, TCM $(52 \%, n=481)$, "neuraltherapy" $(20 \%, n=190)$,

\section{Discussion}

The present survey compared CAM with CM in terms of perceived effectiveness, side-effects, compliance, and costs, as these were experienced and communicated by the respondents. The results are based on the questionnaires filled out by adults-in $99 \%$ of the cases parents-accompanying pediatric patients presenting to the emergency unit, and reflect the experiences that they had so far. Most of them (58\%, 665 of 1143) had experienced some form of CAM. ${ }^{22}$

When asked to describe the perceived effectiveness of CAM and CM independently from each other, the respondents rated CAM as being somewhat less effective than CM. However, when asked to directly compare the perceived effectiveness of CAM therapies with that of CM, $62 \%$ of the respondents described CAM to be either "more effective in certain cases/against certain disorders than" or "equivalent effective to" CM. We interpret these results as indicating that although the respondents had the impression that in a general way CM is more effective than CAM, the majority of the respondents had already experienced situations in which CAM was at least as effective as CM.

The side-effects of CAM therapies turned out to be clearly more seldom and weaker than those of CM. This constitutes the most marked difference between the two types of therapies, which was revealed by the present survey, with the representative value for CAM being four times lower than the one for CM. Nevertheless, $6 \%$ of the respondents did notice weak side-effects and $1 \%$ even strong side-effects upon the use of CAM therapies, which is in disagreement with the widespread belief that CAM is harmless.

Taken together, the results on perceived effectiveness and tolerability suggest that although CAM might be slightly less effective than $\mathrm{CM}$, its good performance in some clinical situations and the superior tolerability leads to a high satisfaction of the users, which might explain the widespread use of CAM among the respondents $\left(58 \%{ }^{22}\right)$. These observations seem to justify the recommendation of CAM therapies in certain situations, if accompanied by an individual assessment of the patient's risk situation by a medical doctor. 
Table 1. List of the Complementary and Alternative Medicine (CAM) Therapies Mentioned by the Respondents as Being Used by the Accompanying Pediatric Patient and Corresponding Extent of Self-Medication

\begin{tabular}{|c|c|c|c|c|c|c|c|}
\hline \multirow[b]{2}{*}{ CAM therapies used } & \multirow[b]{2}{*}{$\mathrm{n}$} & \multirow[b]{2}{*}{$\%^{\mathrm{a}}$} & \multicolumn{2}{|c|}{ Self-medication } & \multicolumn{2}{|c|}{ Prescribed } & \multirow[b]{2}{*}{$S / P$-factor } \\
\hline & & & $\mathrm{n}$ & $\%^{\mathrm{a}}$ & $\mathrm{n}$ & $\%^{\mathrm{a}}$ & \\
\hline Homeopathy: & 511 & $77 \%$ & 406 & $61 \%$ & 232 & $35 \%$ & 1.8 \\
\hline Mixed medicaments on sale & 151 & $23 \%$ & 123 & $18 \%$ & 65 & $10 \%$ & 1.9 \\
\hline Individual medicaments (classical homeopathy) & 225 & $34 \%$ & 134 & $20 \%$ & 139 & $21 \%$ & 1.0 \\
\hline Bach Flower Remedies & 347 & $52 \%$ & 286 & $43 \%$ & 145 & $22 \%$ & 2.0 \\
\hline Phytotherapy (herbal medicine): & 426 & $64 \%$ & 305 & $57 \%$ & 363 & $21 \%$ & 0.8 \\
\hline Herbal medicaments on sale & 45 & $7 \%$ & 38 & $6 \%$ & 30 & $5 \%$ & 1.3 \\
\hline Herbal cough tea, digestive potions, etc. & 91 & $14 \%$ & 52 & $8 \%$ & 67 & $10 \%$ & 0.8 \\
\hline Herbal creams (bronchial balsam, etc.) & 122 & $18 \%$ & 73 & $11 \%$ & 77 & $12 \%$ & 0.9 \\
\hline Compresses (with onions, vinegar etc.) & 156 & $23 \%$ & 136 & $20 \%$ & 50 & $8 \%$ & 2.7 \\
\hline Others & 308 & $46 \%$ & 175 & $26 \%$ & 281 & $42 \%$ & 0.6 \\
\hline Anthroposophic medicine: & 158 & $24 \%$ & 115 & $17 \%$ & 87 & $13 \%$ & 1.3 \\
\hline Medicaments & 23 & $3 \%$ & 12 & $2 \%$ & 19 & $3 \%$ & 0.6 \\
\hline Compresses and massages & 38 & $6 \%$ & 31 & $5 \%$ & 21 & $3 \%$ & 1.5 \\
\hline Kinesitherapy (eurhythmia) & 15 & $2 \%$ & 9 & $1 \%$ & 11 & $2 \%$ & 0.8 \\
\hline Linguistic therapy, music therapy & 66 & $10 \%$ & 28 & $4 \%$ & 52 & $8 \%$ & 0.5 \\
\hline Nutrition (bioenergetic) & 78 & $12 \%$ & 54 & $8 \%$ & 36 & $5 \%$ & 1.5 \\
\hline Others & 37 & $6 \%$ & 18 & $3 \%$ & 22 & $3 \%$ & 0.8 \\
\hline TCM & 89 & $13 \%$ & 52 & $8 \%$ & 52 & $8 \%$ & 1.0 \\
\hline Acupuncture with needle & 27 & $4 \%$ & 24 & $4 \%$ & 23 & $3 \%$ & 1.0 \\
\hline Acupuncture with laser & 26 & $4 \%$ & 25 & $4 \%$ & 21 & $3 \%$ & 1.2 \\
\hline Acupressure (Shiatsu) & 11 & $2 \%$ & 10 & $1 \%$ & 11 & $2 \%$ & 0.9 \\
\hline Herbal medicine & 22 & $3 \%$ & 17 & $3 \%$ & 15 & $2 \%$ & 1.1 \\
\hline Kinetotherapy (yoga) & 24 & $4 \%$ & 20 & $3 \%$ & 13 & $2 \%$ & 1.5 \\
\hline Nutrition, diet & 25 & $4 \%$ & 16 & $2 \%$ & 14 & $2 \%$ & 1.1 \\
\hline Others & 33 & $5 \%$ & 23 & $3 \%$ & 13 & $2 \%$ & 1.8 \\
\hline Ayurveda & 36 & $5 \%$ & 30 & $5 \%$ & 11 & $2 \%$ & 2.7 \\
\hline Medicaments & 13 & $2 \%$ & 10 & $2 \%$ & 5 & $1 \%$ & 2.0 \\
\hline Massages, wellness, meditation & 27 & $4 \%$ & 24 & $4 \%$ & 9 & $1 \%$ & 2.7 \\
\hline Others & 36 & $6 \%$ & 33 & $5 \%$ & 7 & $1 \%$ & 4.7 \\
\hline Other therapies: & 224 & $34 \%$ & 184 & $28 \%$ & 83 & $12 \%$ & 2.2 \\
\hline Natural vitamins (supplements) & 114 & $17 \%$ & 95 & $14 \%$ & 38 & $6 \%$ & 2.5 \\
\hline Schüssler-salt & 66 & $10 \%$ & 54 & $8 \%$ & 20 & $3 \%$ & 2.7 \\
\hline Reflexology & 27 & $4 \%$ & 21 & $3 \%$ & 10 & $2 \%$ & 2.1 \\
\hline Neuraltherapy & 3 & $0 \%$ & 3 & $0 \%$ & 1 & $0 \%$ & 3.0 \\
\hline Bioresonance therapy & 44 & $7 \%$ & 10 & $2 \%$ & 24 & $4 \%$ & 0.4 \\
\hline Others & 52 & $8 \%$ & 42 & $6 \%$ & 17 & $3 \%$ & 2.5 \\
\hline
\end{tabular}

a Percentage of all CAM users.

CAM, complementary and alternative medicine; S/P-factor, ratio between self-medication and therapies prescribed by physician; TCM, Traditional Chinese Medicine.

Slightly lower compliance and higher frequency of use were observed in the case of CAM, relatively to CM, suggesting different behaviors of the respondents toward the two types of medicinal systems. Interestingly, $12 \%$ of the children had never made use of CM and $17 \%$ did not use CAM therapies, revealing that either a considerable proportion of this population had been in very good health or that the parents refrained from going to a physician.

The direct costs for the patient of both types of medicine were comparable, with a tendency for higher costs being apparent in the case of CM. In Switzerland, the costs for CM are almost entirely covered by the obligatory health insurance. However, the costs for CAM are at present only reimbursed by the obligatory insurance in exceptional cases, and patients have to arrange for additional insurance if they wish CAM therapies to be reimbursed. Since a considerable number of the respondents did not have such an additional insurance for CAM, the present data on the direct costs of both types of medicine might indicate that in general CM is more expensive than CAM. Higher costs for CM relatively to CAM have been detected previously by PEK, when comparing the total annual costs of CM- and CAM physicians and the corresponding medication costs. ${ }^{15}$

Fifty-three percent (53\%) of the pediatric patients had an additional health insurance for CAM, corroborating the previously published value (approximately 50\% ${ }^{15}$ ) for the entire Swiss population. While this percentage was clearly higher in the case of CAM users, it is surprising that $37 \%$ of the nonusers possess this insurance as well. A possible explanation for this discrepancy might be that the insurance companies often offer an additional health insurance for CAM within a commercial package that comprises several other products. The majority of all respondents (96\%) were in favor of the inclusion of some CAM therapies in the basic health insurance. This value outruns the results of a Swiss voting in favor of CAM, which took place in May 
FIG. 3. Respondents' opinions on which medical systems should be included in the basic health insurance and taught at the universities. Respondents were asked if conventional medicine,

homeopathy, herbal medicine, anthroposophic medicine, Traditional Chinese Medicine (TCM), neuraltherapy, and others should be included in the basic health insurance (black columns) and taught at the universities (white columns). Data are shown as percentage of all answers.

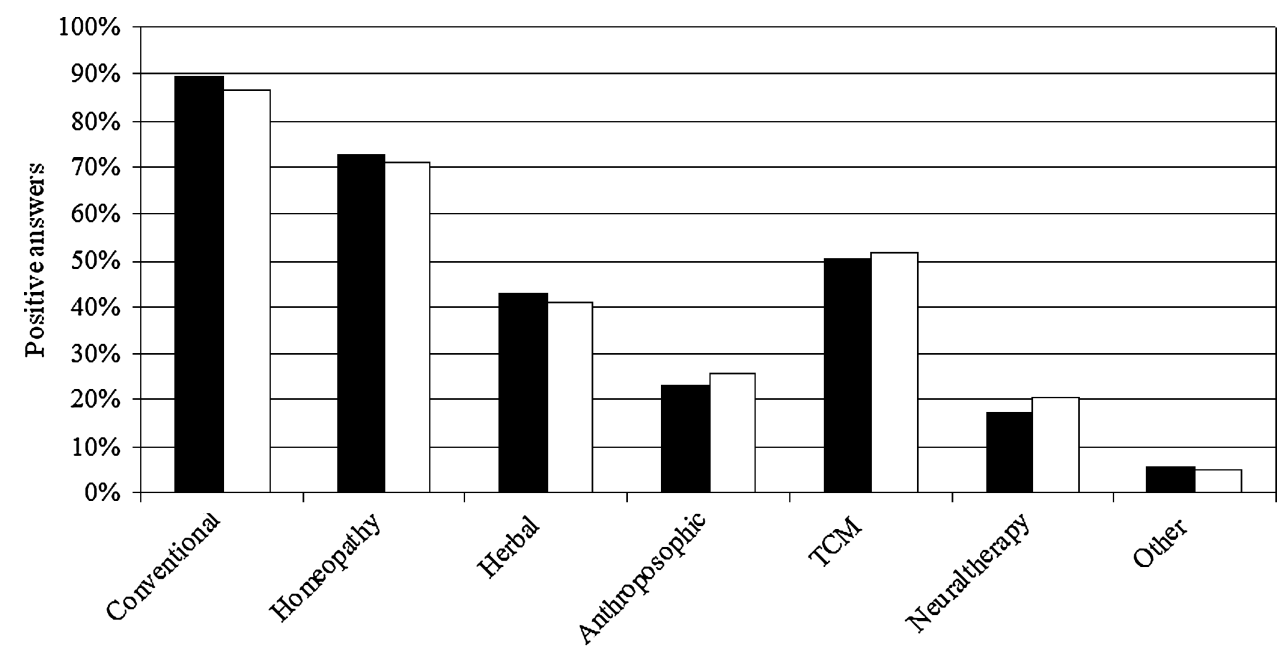

Medical systems should be included in basic health insurance

$\square$ Medical systems should be taught at the universities
2009; the results of this voting in the region of Zurich showed that $62.4 \%$ of the voters had a positive attitude toward CAM. $^{24}$

One of our goals was to find out exactly which therapies the pediatric patients had used. While the questionnaire used in the present survey allowed us to identify a wide variety of CAM therapies, it should be noted that no attempt was made to mention only clearly therapeutic items; some items that might be considered under the category wellness/sports were allowed. The respondents mentioned a notorious variety of CAM therapies (depicted in Table 1) as having been used by the pediatric patients. A recent survey on family doctors in Switzerland shows that $30 \%$ of them do practice some form of CAM: 34\% homeopathy, 34\% herbal medicine (phytotherapy), $31 \%$ TCM/acupuncture, $11 \%$ anthroposophic medicine, $11 \%$ neuraltherapy, and $30 \%$ others. ${ }^{25}$ Our data corroborate that homeopathy is the most used CAM therapy, followed by herbal medicine. The detected use of anthroposophic medicine (24\% of all CAM users), however, was higher and that of TCM/acupuncture (13\%) was lower in the present survey. Finally, neuraltherapy seems not to be practiced in children $(0 \%)$.

A previous report on this survey showed that two thirds of the administered CAM therapies could be attributed to self-medication. $^{22}$ This high extent of self-medication might be worrying because side-effects, intoxications, and interactions between CAM and conventional therapies can occur. $^{26-29}$ Some self-medication was reported in essentially all types of the CAM therapies; still, a few differences of the extent of self-medication among the various therapies were detected. The low numbers of respondents using some of the therapies mentioned under "others" prevent a proper interpretation of the corresponding data.

The major limitations of the study are the lack of clinical data and the exclusion of respondents who could not read or write German, English, French, or Italian. The limited number of available linguistic versions of the questionnaires might explain why Swiss people seem to be overrepresented in this survey: Whereas $21 \%$ of the people living in Canton Zurich are foreigners, ${ }^{30}$ only $8 \%$ of the pediatric patients were not born in Switzerland. Another explanation is that due to the long process needed to acquire Swiss citizenship, the number of children classified as foreigners is probably much higher that the number of children actually born outside of Switzerland. Further limitations of our study might be a rather wide definition of CAM, the confinement of the survey to one emergency unit only, and the use of common language expressions—such as "all," "never," "sometimes"—without further (numerical) definition of what is exactly meant.

Strengths of the present survey are the high number of respondents and the elevated response rate, answering of the questionnaire in privacy, and the absolute protection of anonymity of the respondents. Because the approach followed in a survey is markedly different from those of interventional clinical trials, our data add qualitatively different information to several trials designed to compare defined CAM therapies and $\mathrm{CM}$ therapies with respect to effectiveness, side-effects, compliance, and/or costs.

Taken together, the data presented here show that for the respondents, adults accompanying pediatric patients presenting to the emergency department, the strongest difference between CM therapies and CAM therapies concerned the tolerability of the two types of medicinal systems, with clearly more seldom and weaker side-effects being experienced with CAM therapies. Within the wide range of CAM therapies that had been used by those pediatric patients, preferences for homeopathy, herbal medicine, and anthroposophic medicine could be detected.

\section{Acknowledgments}

We would like to thank the staff, parents, and children of the pediatric emergency department of Children's Hospital of Zurich for their time and cooperation. The multilingual translation of Anita Staubli is gratefully acknowledged. This publication was financially supported by the ParacelsusHospital of Richterswil (Switzerland) and the Johannes Kreyenbühl Academie.

\section{Disclosure Statement}

No competing financial interests exist. 


\section{References}

1. Eisenberg DM, Davis RB, Ettner SL, et al. Trends in alternative medicine use in the United States, 1990-1997: Results of a follow-up national survey. JAMA 1998;280:1569-1575.

2. Wetzel MS, Eisenberg DM, Kaptchuk TJ. Courses involving complementary and alternative medicine at US medical schools. JAMA 1998;280:784-787.

3. Yates KM, Armour MJ, Pena A. Complementary therapy use amongst emergency medicine patients. Complement Ther Med 2009;17:224-228.

4. Southwood TR, Malleson PN, Roberts-Thomson PJ, et al. Unconventional remedies used for patients with juvenile arthritis. Pediatrics 1990;85:150-154.

5. Sawyer MG, Gannoni AF, Toogood IR, et al. The use of alternative therapies by children with cancer. Med J Aust 1994;160:320-322.

6. Friedman T, Slayton WB, Allen LS, et al. Use of alternative therapies for children with cancer. Pediatrics 1997;100:E1.

7. Andrews L, Lokuge S, Sawyer M, et al. The use of alternative therapies by children with asthma: A brief report. J Paediatr Child Health 1998;34:131-134.

8. Sawni A, Ragothaman R, Thomas RL, et al. The use of complementary/alternative therapies among children attending an urban pediatric emergency department. Clin Pediatr (Phila) 2007:46:36-41

9. Pitetti R, Singh S, Hornyak D, et al. Complementary and alternative medicine use in children. Pediatr Emerg Care 2001;17:165-169.

10. Losier A, Taylor B, Fernandez CV. Use of alternative therapies by patients presenting to a pediatric emergency department. J Emerg Med 2005;28:267-271.

11. Langler A, Spix C, Gottschling S, et al. Parents-interview on use of complementary and alternative medicine in pediatric oncology in Germany [in German]. Klin Padiatr 2005;217: 357-364.

12. Wolf U, Maxion-Bergemann S, Bornhoft G, et al. Use of complementary medicine in Switzerland. Forsch Komplementmed 2006;13(suppl 2):4-6.

13. Widmer M, Donges A, Wapf V, et al. The supply of complementary and alternative medicine in Swiss hospitals. Forsch Komplementmed 2006;13:356-361.

14. Jenny S, Simon M, Meier B. People's attitude towards complementary medicine [in German]. Schweiz Z Ganzheitsmedizin 2002;14:340-347.

15. Melchart D, Mitscherlich F, Amiet M, et al. Programm Evaluation Komplementärmedizin (PEK)-Schlussbericht. 2005. Online document at: www.bag.admin.ch/themen/ krankenversicherung/00263/00264/04102/index.html?lang= de Accessed January 5, 2010.

16. Bundesamt für Statistik, B.F.S., Schweizerische Gesundheitsbefragung. 2002. Standardtabellen Niveau Schweiz. 2002. Online document at: www.bfs.admin.ch/bfs/portal/ de/index/themen/14/22/publ.html?publicationID $=1357$ Accessed January 5, 2010.

17. Bornhoft $G$, Wolf $U$, von Ammon $K$, et al. Effectiveness, safety and cost-effectiveness of homeopathy in general practice: Summarized health technology assessment. Forsch Komplement Med 2006;13(suppl 2):19-29.

18. Kienle GS, Kiene H, Albonico HU. Anthroposophic medicine: Health technology assessment report. Short version [in German]. Forsch Komplementarmed 2006;13(suppl 2):7-18.

19. Maxion-Bergemann S, Bornhoft G, Sonderegger E, et al. Traditional Chinese medicine (phytotherapy): Health Technology Assessment report. Selected aspects. Forsch Komplementmed 2006;13(suppl 2):30-41.

20. Walach $H$, Heusser P. Effective or not? The decision is yours! The PEK HTA reports [in German]. Forsch Komplementmed 2006;13(suppl 2):2-3.

21. Moenkhoff $M$, Baenziger $O$, Fischer J, et al. Parental attitude towards alternative medicine in the paediatric intensive care unit. Eur J Pediatr 1999;158:12-17.

22. Zuzak TJ, Zuzak-Siegrist I, Simões-Wust AP, et al. Use of complementary and alternative medicine by patients presenting to a Paediatric Emergency Department. Eur J Pediatr 2009;168:431-437.

23. Zuzak TJ, Zuzak-Siegrist I, Rist L, et al. Attitudes towards vaccination: Users of complementary and alternative medicine versus non-users. Swiss Med Wkly 2008;138:713-718.

24. Tagesanzeiger. Klares Ja zur Komplementärmedizin. 2009. Online document at: www.tagesanzeiger.ch/schweiz/ standard/Klares-Ja-zur-Komplementaermedizin/story/24525215 Accessed January 5, 2010.

25. Deglon-Fischer A, Barth J, Ausfeld-Hafter B. Complementary and alternative medicine in primary care in Switzerland [in German]. Forsch Komplementmed 2009;16: 251-255.

26. Woolf AD. Herbal remedies and children: Do they work? Are they harmful? Pediatrics 2003;112:240-246.

27. Jankovic M, Spinetta JJ, Martins AG, et al. Non-conventional therapies in childhood cancer: guidelines for distinguishing non-harmful from harmful therapies: A report of the SIOP Working Committee on Psychosocial Issues in Pediatric Oncology [in German]. Klin Padiatr 2004;216:194-197.

28. Cohen MH, Kemper KJ. Complementary therapies in pediatrics: A legal perspective. Pediatrics 2005;115:774-780.

29. Drew AK, Myers SP. Safety issues in herbal medicine: Implications for the health professions. Med J Aust 1997; 166:538-541.

30. Statistisches Amt des Kantons Zürich. Bevölkerung im Kanton Zürich 1980-2000. Online document at: www. statistik.zh.ch/statistik.info/pdf/2001_15.pdf Accessed on January 5, 2009.

Address correspondence to: Ana Paula Simões-Wüst, Ph.D. Research Department Paracelsus Hospital Richterswil Bergstrasse 16 Richterswil 8805 Switzerland

E-mail: simoes@paracelsus-spital.ch 
